Indexed by

\title{
Scopus
}

\section{A REVIEW OF VIBRO-ACOUSTIC TECHNIQUES FOR CONTROL OF COMBUSTION ENGINE NOISE}

\section{S Narayan}

Qassim University, Mechanical Engineering Department, Buraydah, Saudi Arabia
Muhammad Usman Kaisan

Ahmadu Bello University, Mechanical Engineering Department, Zaria, Nigeria

\section{Shitu Abubakar}

Ahmadu Bello University, Mechanical Engineering Department, Zaria, Nigeria

Key words: engine acoustics, condition monitoring, signal processing diagnoses doi:10.5937/jaes0-29675

Cite article:

Narayan S., Kaisan Usman M., Abubakar S. (2021) A REVIEW OF VIBRO-ACOUSTIC TECHNIQUES FOR CONTROL OF COMBUSTION ENGINE NOISE, Journal of Applied Engineering Science, 19(4), 880 - 885, DOI:10.5937/ jaes0-29675

Online aceess of full paper is available at: www.engineeringscience.rs/browse-issues 


\title{
A REVIEW OF VIBRO-ACOUSTIC TECHNIQUES FOR CONTROL OF COMBUSTION ENGINE NOISE
}

\author{
S Narayan ${ }^{1 *}$, Muhammad Usman Kaisan ${ }^{2}$, Shitu Abubakar ${ }^{2}$ \\ ${ }^{1}$ Qassim University, Mechanical Engineering Department, Buraydah, Saudi Arabia \\ ${ }^{2}$ Ahmadu Bello University, Mechanical Engineering Department, Zaria, Nigeria
}

The present work focuses on various vibro-acoustic signals techniques that can monitor malfunctions in Internal Combustion Engines (ICEs). Recent works by other authors have focused on various reciprocating machines including compressors no attempts has been deal with IC engines. This paper gives a summary of the generation mechanism of sound and vibration in Engines. An overview of the monitoring and diagnostic techniques base on noise, pressure an vibration signatures is also discussed. Various fault conditions are described which affect ICEs. Measuring of acoustic signals has non-intrusive behavior with capability of detecting airborne transmission paths faults. In view of industrial needs to reduce the maintenance costs monitoring of vehicle operations, the present work can be a useful guide for engineers for understanding types of faults so as sufficient time is obtained to process reliable and information.

Key words: engine acoustics, condition monitoring, signal processing diagnoses

\section{INTRODUCTION}

Monitoring of in cylinder pressure developed, noise, vibration andacoustic signals are some of these techniques commonly used for analysis of working of machines [1]. However, there are is risk of contamination of signals due to interfering from surroundings. Signal acquiring, processing and finally extraction of various features are steps for fault diagnosis [2]. Various diagnosis methodologies allow effective monitoring of combustion engines in order to allow preventive maintenance and hence allow ability to detect various faults before it can cause any actual damage to machine. The early detection of faults has both advantages both in terms of cost as well as time. These methodologies allow the downtime of maintenance to be scheduled, prevent sudden shutdown of machines or risks of any potential injury to operators. Diesel engine pressure, vibrations and noise emissions data is a rich source of information about physical conditions and operational parameters [1]. The following section provides details about various diagnosis methodologies adopted in case of diesel engines for condition methodologies.

A. Vibration monitoring -It is most commonly used methodology, but effective location of transducer is a big challenge as mixing of signals may occur due to different transmission paths. Vibration signals can be analyzed by frequency spectrum, peak or RMS values. These can be used to monitor various imbalances, bearing damage or shaft misalignments [1].

B. In cylinder pressure monitoring- Data about cylinder pressure analysis provides information about injector faults, wear, valve problems, incorrect injection timings and hence overall combustion efficiency of engines, however high temperature conditions make various pressure sensors expensive with short life time [2].
C. Noise emissions - Noise levels are perceived by the humans as the air pressure oscillations reach human ears which leads to the motion of the ear drums. Various sound features can be analyzed by means of sound pressure levels (SPL) and frequency with equal loudness contours. In order to obtain the levels which bears a closer relationship to loudness judgment than the sound pressure levels, three different networks of frequency weighting $(A, B$, and C) were incorporated into various sound level meters with the A-weighting most closely matches the human ear [3].

Due to higher compression ratios, diesel engines are known to produce higher noise emissions as compared to gasoline engines [4,5]. Higher compression ratio increases various forces on piston assembly at the ignition time that results in overall increase in vibrations of engine structure. Overall this leads to increase in noise emissions from engine. Due to large number of external effects the acceleration and noise emissions data may become contaminated leading to complexities. Hence various signal processing methods can reveal information about these events which have fixed time of occurrence depending upon the crank mechanism of engine. These methods Short Time Fourier Transformations (STFT), Wavelet Transformation (WT), Bilinear Time-frequency Distribution (BTFD) [6]. Winger -Ville distribution (WVD), Born -Jordan distribution (BJD) and Choi-Williams distribution (CWD) are commonly used BTFD methods [7]. When these methods are applied to transient signals, large ripples are produced on the envelopes which may lead to loss of information [8]. However, these methods have better frequency as well as time resolutions when compared to conventional Fourier 
transformations. In this part of work some of the commonly used signal processing techniques have been discussed. Various important properties of these methods have been presented, and finally their performance was evaluated by application on the data acquired from engine, operating it at different testing conditions.

This work presents a comprehensive study of these techniques, and hence can be important source of information to understand behavior of engines.

\section{LITERATURE REVIEW}

Hambric et al. [3] studied ways to optimize structures to reduce vibrations. Nuawi et al. [4] proposed statistical approach to characterize the fatigue strength of metallic material. Ji et al. [5] reviewed modelling of extruded aluminum train floor structures to predict vibro-acoustic responses. Duffour monitored modulation of an ultrasonic vibrations through a cracked specimen [6]. Creixell studied optimization of hearing aid sources [7].Aymerich et al. [8]studied damage due to impacts in composite laminates. Trochidis et al. [9] investigated nonlinear features of Zhao-Atlas-Marks (ZAM) distribution. A more sensitive novel index was defined that was correlated to crack size. Urban et al. [10] presented an overview of vibro-acoustic ctechniques in biomedicine. Jia et al. [11] developed a load insensitive damage index (LIDI) to track the crack growth. Anwar focused on gear box vibrations obtained from surface of engines [12]. Wang et al. [13] proposed fuzzy parameter based study of dynamic and acoustic properties of coupled systems. Gorski et al. [14] used signal processing to study the wear in tools. Hipol studied finite element analysis of aerospace structures [15]. Mohanty et al. [16] predicted behavior of engine bearing with adaptive noise algorithms. Cheng et al. [17] predicted start of combustion in diesel engines using cylinder head vibration velocity. Dykas et al. [18] used acoustic emission sensing techniques for fault diagnosing. Flett et al. [19] used Naïve-Bayes method for valve train detection diagnosis.

The main focus of present work is on study of combustion based excitation and piston lateral motion as these have major contributions towards engine noise emissions. Some of the major works related to present work are enlisted in table no 1

\section{SIGNAL PROCESSING TOOLS}

\section{A. Power spectral density function}

This function $\left(\Psi^{2}\right)$ denotes a random process which provides the frequency composition of data in terms of its mean square value [9]. The mean square value of a time sample in frequency range $[\omega, \omega+\Delta \omega]$ can be obtained by passing sample through a band pass filter with sharp cutoff frequency features and then computing the average of squared output from filter. The average square value approachs mean square value as $\mathrm{T} \rightarrow \infty$.i.e.

$\Psi^{2}(\omega, \Delta \omega)=\operatorname{Lim}_{\Delta x \rightarrow \infty} \frac{\int_{0}^{T} x^{2}(t) d t}{T}$

\section{B. Time frequency analysis}

The Fourier transformation of a function $\mathrm{f}(\mathrm{t})$ in frequency domain can be represented as:

$$
f(\omega)=\int_{0}^{t} f(t) e^{-j \omega t} d t
$$

This analysis is useful as long as frequency content of signals do not vary with time. Hence time-frequency analysis or wavelet analysis are more suitable [10]. Time -frequency analysis is suitable for analysis of signals having slow frequency changes such as those generated during engine ramp down, whereas wavelet analysis is more suited for fast frequency changes such as those generated during rattle [11]. In the time-frequency analysis the signal is windowed into small intervals and then Fourier transformation is taken for each interval [12].

Length of window can be used to change the resolution of the output signal. A shorter window has higher reso-

Table 1: Summary of research works related to present work

\begin{tabular}{|c|c|c|c|}
\hline Author & Engine used & Method used & Aim \\
\hline $\begin{array}{c}\text { Jung, I., Jin, J., So, H., } \\
\text { Nam, C. et al.[19] }\end{array}$ & 4 cylinder diesel engine & Variations in fuel injection & $\begin{array}{c}\text { Development of various } \\
\text { noise related indices }\end{array}$ \\
\hline $\begin{array}{c}\text { Ingemar Andersson, To- } \\
\text { mas McKelvey, Martin } \\
\text { Larsson[20] }\end{array}$ & 6 cylinder diesel engine & Vibrational energy & $\begin{array}{c}\text { Estimating combustion phas- } \\
\text { ing parameters }\end{array}$ \\
\hline $\begin{array}{c}\text { Zhenpeng He,Weisong } \\
\text { Xie, Guichang Zhang, } \\
\text { Zhenyu Hong, Junhong } \\
\text { Zhang[21] }\end{array}$ & 4 cylinder diesel engine & $\begin{array}{c}\text { Simulation of lateral mo- } \\
\text { tion of skirt }\end{array}$ & $\begin{array}{c}\text { Observe the effects of geo- } \\
\text { metrical parameters of skirt } \\
\text { on piston lateral motion }\end{array}$ \\
\hline $\begin{array}{c}\text { N.Dolatabadi, B.Littlefair, } \\
\text { M.Dela Cruz,S. Theo- } \\
\text { dossiades, S.J.Roth- } \\
\text { berg, H. Rahnejat[22] }\end{array}$ & 1 cylinder gasoline engine & $\begin{array}{c}\text { Analysis of engine block } \\
\text { accelerations }\end{array}$ & $\begin{array}{c}\text { Identification of locations of } \\
\text { various slapping events }\end{array}$ \\
\hline $\begin{array}{c}\text { Yeow-Chong Tan, Zaidi } \\
\text { Mohd Ripin[23] }\end{array}$ & 4 cylinder diesel engine & Lumped mass approach & $\begin{array}{c}\text { Simulation of resulting block } \\
\text { vibrations }\end{array}$ \\
\hline
\end{tabular}


lution in time domain, but a poor resolution in frequency domain and vice versa. Higher time resolution at higher frequencies makes it possible to resolve short consecutive events using wavelet transformation. The short time frequency analysis is based on expansion of signal into a set of weighted frequency modulated Gaussian functions and may be represented as:

$$
\operatorname{STFT}(T, f)=\int_{0}^{T} x(t) h^{*}(t-T) e^{-j \omega t} d t
$$

Where $x(t)$ is input signal \& $h(t-T)$ is window function. Wigner Ville function has following quadratic time-frequency distribution represented by [9]:

$$
\operatorname{STFT}(T, f)=\int_{0}^{T} x\left(t-\frac{T}{2}\right) x^{*}\left(t+\frac{T}{2}\right) e^{-j \omega t} d t
$$

\section{Wavelet Analysis}

Wavelet analysis maps a signal on joint time -frequency plane and is sensitive towards the transient nature of signals. One of the major drawbacks of various time-frequency processing methods is that they produce ripples, hence making it difficult extract valuable information [13] During wavelet analysis, the frequency resolution is better at low frequencies whereas the time resolution is better at higher ones. Hence Wavelet analysis results are more accurate as compared with other methods [14]. Using wavelet method, a signal is transformed onto a family of zero mean functions which are known as wavelets. These have high time resolution and have no cross-term interference. The power spectral density function (PSD) is similar to the short-time-frequency analysis, whereas the wavelet transformation represents a linear transformation. The squared wavelet transform is called a scalogram. A single scalogram can easily cover audible frequency range with a time resolution of approximately 0.1 $\mathrm{ms}$ for the high-frequency components [11].

This makes scalogram more suitable for such various signals like squeak and rattle noise for which a wide range of frequency analysis is needed.

Mathematically for a function $f(t)$, a complex wavelet transform is defined by [15]:

$$
C W T(a, b)=\int_{-\infty}^{+\infty} f(t) \frac{1}{\sqrt{a}} \frac{\psi(t-b)}{a} d x
$$

Where

$\psi(t)$ : Mother wavelet, $f(t)$ : Analyzed signal, a: Scaling factor, b: Shifting factor

\section{CWT $(a, b)$ : wavelet coefficients}

Mother Wavelet function $\psi(\mathrm{t})$ must satisfy following conditions:

A. This function has zero average and decays exponentially to zero. i.e.

$\int_{-\infty}^{+\infty} \psi(t) d t=0$

B. Function and its Fourier transformation must satisfy admissibility condition. i.e.

$$
\int_{-\infty}^{+\infty} \frac{\psi(t)^{2}}{|f|} \leq 0
$$

Both dilation as well as translation parameters in CWT are subjected to variations that makes its use more complex. Discretization of signals can help to reduce this problem to certain extent. The CWT of a signal discrete signal $X_{m}$ is defined in terms of sampling time $\Delta t$ and sample data points $\mathrm{m}, \mathrm{n}$ as:

$C W T=\sum_{m=0}^{N-1} X_{m} \psi^{*}\left[\frac{(m-n) \Delta t}{X_{j}}\right]$

Where $\mathrm{t}=\mathrm{m} \Delta \mathrm{t}, \mathrm{b}=\mathrm{n} \Delta \mathrm{t}, \mathrm{m}$ \& $\mathrm{n}$ varies from $0,1,2 \ldots \mathrm{N}-1, \mathrm{~N}$

\section{SOURCES OF NOISE AND VIBRATIONS IN ENGINE}

Performance valuation of automotive engines is needed for designing and planning of systems. This includes testing of various engines of different configurations using variations in fuel injections conditions [1, 2, 3]. Structure borne and air borne noise are two major sources. The type of noise in air is known as air borne noise, whereas low frequency sound entering via structural path is known as structure borne noise. The experimental and analytical investigations includes:
A. Overall sound pressure level measurements.
B. Ranking as well as identification of sources.
C. Study of transfer paths.
D. Subjective and objective valuations

This portion of work discusses features of various sources of noise found in an engine.

A. Combustion based noise -Combustion is an important process for designing and performance calibration of automotive system. The noise and vibrations from combustion are transmitted via liner walls, cylinder walls and connecting rod to surroundings. Structural attenuation also effects the noise radiated from engine. Higher stiffness of bore leads to higher values of resonant frequencies. A reduction in the Combustion delay period leads to lower values of combustion noise. Compression ratios, intake air pressure, exhaust gas recirculation and structural attenuation of various parts also effects this source of noise [20].

B. Piston skirt noise -Pin tickling, piston secondary motion and rattling are major sources of noise in piston. Piston lateral motion noise has major contributions in piston assembly that is dominant under idle cold starting conditions [21].

C. Valve motion noise -This higher frequency noise includes following three major sources:

- Acceleration of CAM-Opening and closure of causes higher frequency vibrations.

- Valve impacts -These impulsive bouncing motions are observed during opening and closure of valves between cam, follower and valve seat at higher speeds.

- Frictional vibrations-These low speed vibrations arise from asperity contact between cam and follower. 


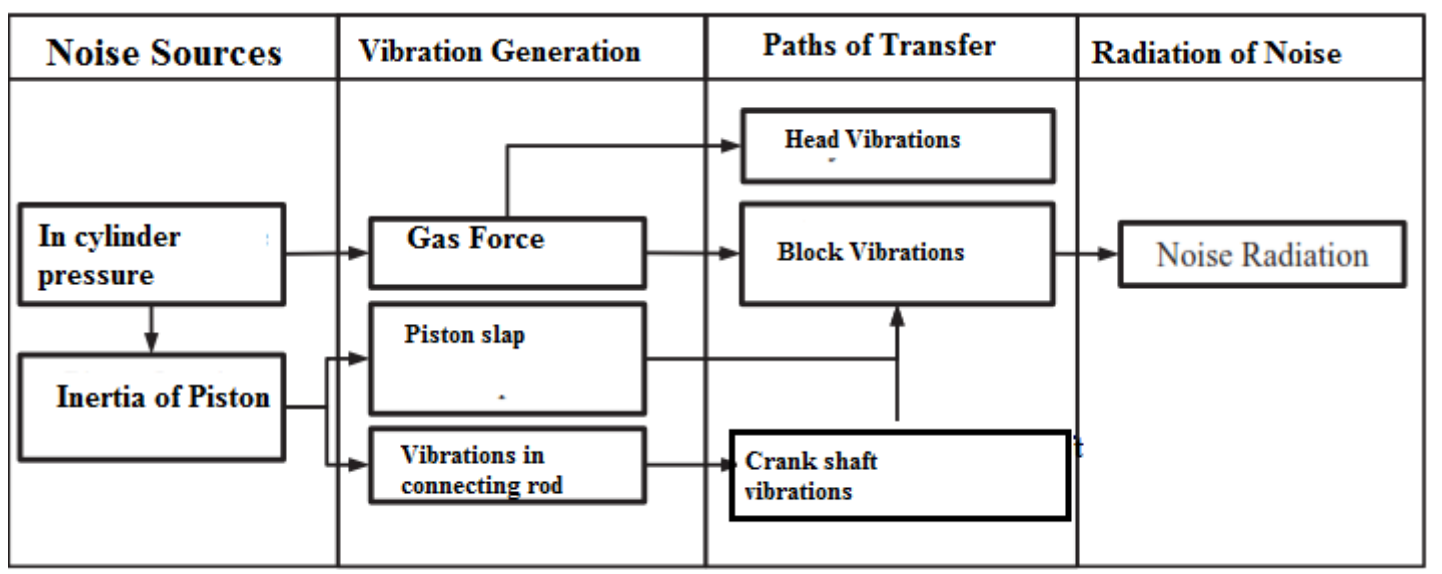

Figure 1: Mechanism of noise generation

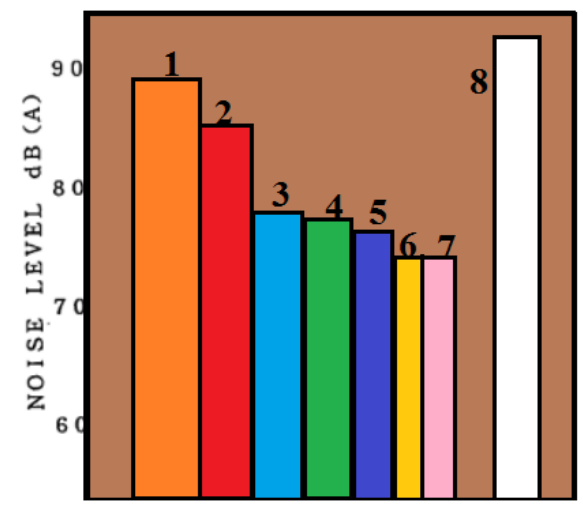

Figure 2: The total noise contribution (8) can be decomposed into contributions due to combustion noise (1), contribution due to piston slap noise (2), contribution due to fan noise (3), contribution to gear operation noise(4), contribution due to pump operations (5), valve noise (6) and other sources (7)

D. Gear train noise -The rattle noise due to non-uniform torque from crank train to drive observed during transmissions is a primary cause of concern[22]. Clearances in meshing tooth of causes vibrational impacts gears at lower engine speeds. Tooth deflection is a major source of whining noise. This noise dependent on the number and size of meshing tooth, torsional inputs and location of gear train [23].

E. Flow noise -Low frequency intake noise due to turbulence at inlet ducts depends on the valve area and speed. [24]. Charging and discharging in the exhaust duct causes exhaust noise [25]. Turbocharging is also important source of aerodynamic noise.

F. Bearing noise -bearings in crankshaft and connecting rod have clearances that generate noise [26]. Torsional and bending resonance give rise to rumbling noise [27]. Clearance optimization of, application of crank shaft damper and flexible flywheel design may be used to control this sour of noise.

G. Belt and chain noise-Meshing impact and polygon effect depends on tension, speed and number of meshing teeth [28-45].

\section{CONCLUSIONS}

The combustion and piston motion noise have major contributions, hence it is necessary to analyze in more depths these aspects of engine noise and vibration acoustics. Figure no 1 depicts generation mechanism for various sources of noise in an engine with plots of estimated contributions recorded at a distance of $1 \mathrm{~m}$ from engine in an anechoic chamber featured in figure no 2.

As evident from the above figures the combustion based noise and piston slapping noise have major contributing portions (about $80 \%$ ), hence it is necessary to focus on these aspects of engine acoustics. These two features will be discussed in details in further part of this work.

\section{REFERENCES}

1. Kaisan Muhammad Usman, Yusuf Latifat Ovaiyoza, Ibrahim Ibrahim Umar, abubakar Shitu, and Narayan Sunny. (2020). Effects of Propanol and Camphor Blended with Gasoline Fuel on the Performance and Emissions of a Spark Ignition Engine, ACS Omega, Vol. 5, No.41, 26454-26462

2. Sheng, G.(2012).Vehicle noise sound vibration and sound quality, SAE international, Warrendale, Pennsylvania, USA, ISBN- 978-0-7680-3484-4

3. Hambric et al.(2016).Engineering vibroacoustic analysis: methods and applications, ISBN: 978-1119-95344-9. 
4. Nuawi et al.(2013). Time Domain Analysis Method of the Impulse Vibro-acoustic Signal for Fatigue Strength Characterization of Metallic Material, Procedia Engineering, Volume 66,539-548.

5. S.Delvecchioa, P.Bonfigliob, F.Pompol.(2018).Vibro-acoustic condition monitoring of Internal Combustion Engines: A critical review of existing techniques, Mechanical Systems and Signal Processing, Volume 99, 661-683.

6. Philippe Duffour.(2006).A study of the vibro-acoustic modulation technique for the detection of cracks in metals, The Journal of the Acoustical Society of America, Vol. 119, 1463

7. Creixell Mediante, Ester.(2018).Computational reduction techniques for numerical vibro-acoustic analysis of hearing aids. Technical University of Denmark, Department of Electrical Engineering, 176.

8. Aymerich et al.(2010). Experimental Study of Impact-Damage Detection in Composite Laminates using a Cross-Modulation Vibro-Acoustic Technique, Volume 9, Issue 6, 541-553.

9. Trochidis et al.(2014).Analysis of Vibroacoustic Modulations for Crack Detection: A Time-Frequency Approach Based on Zhao-Atlas-Marks Distribution, Shock and Vibration Volume 2014, Article ID 102157, 8 pages, https://doi.org/10.1155/2014/102157.

10. Urban MW, Alizad A, Aquino W, Greenleaf JF, Fatemi M.(2011). A Review of Vibro-acoustography and its Applications in Medicine, Current Medical Imaging Review, Volume 7, Issue 4, 350-359.

11. Jun Jia.(2017). Analysis of load effect on nonlinear vibro-acoustic modulation used in on-line monitoring of fatigue cracks, Smart Materials and Structures, Volume 26, Number 9.

12. Ahmaida, Anwar M.(2018). Condition Monitoring and Fault Diagnosis of a Multi-Stage Gear Transmission Using Vibro-acoustic Signals, Doctoral thesis, University of Huddersfield.

13. Yue Wang, Di Wu, Lei Wang, Xiaojun Wang.(2018). Statistical energy analysis for vibro-acoustic coupled system with fuzzy parameters, Engineering Computations, Volume 35, Issue 2, 565-579.

14. Jarosław Gorski et al.(2019). Use of Cutting Force and Vibro-acoustic Signals in Tool Wear Monitoring Based on Multiple Regression Technique for Compreg Milling, Bioresources, Vol.14, No2

15. Hipol, Philip J.(1989). Finite Element Prediction of Vibro-Acoustic Environments, SAE Transactions, Volume 98, 1881-1889.

16. Mohanty et al.(2015). User Identification of Keystroke Biometric Patterns with the Cognitive RAM Weightless Neural Net, Advances in machine learning and signal processing, Proceedings of MALSIP, Springer International
17. Yong Cheng, Juan Tang, Shaobo Ji, Minli Huang. (2012). Combustion timing determination based on vibration velocity in $\mathrm{HCCl}$ engines, Mechanism and Machine Theory, Volume 58, 20-28.

18. Brian Dykas, James Harris.(2017). Acoustic emission characteristics of a single cylinder diesel generator at various loads and with a failing injector, Mechanical Systems and Signal Processing, Volume 93,397-414.

19. Jung, I., Jin, J., So, H., and Nam, C., 2013,An advanced method for developing combustion noise through the analysis of diesel combustion, SAE Technical Paper 2013-01-1901.

20. Andersson,I.,McKelvey,T., Larsson,M.(2009). Combustion parameters estimation and control using vibration signal : application to the diesel $\mathrm{HCCl}$ engine, Proceedings of the IEEE conference on decision and control.

21. He, Z., Xie,W.,Zhang,G.,Hong,Z.,Zhang,J.(2014). Piston dynamic characteristics analyses based on FEM method Part I: effected by piston skirt parameters, Advances in Engineering Software, Vol 75, 68-85.

22. Dolatabadi et al.(2015).On identification of piston slap events in internal combustion engines using tribo dynamic analysis, Mechanical Systems and signal processing, Vol 58-59, 308-324.

23. Mohd Ripin, Z., and Chong Tan,Y.(2013). Analysis of piston secondary motion, Journal of Sound and Vibration, Vol 332,5162-5176

24. Justin Flett, Gary M. Bone.(2016). Fault detection and diagnosis of diesel engine valve trains, Mechanical Systems and Signal Processing, Volume 72-73, 316-327.

25. Narayan, S.(2014). A review of diesel engine acoustics, FME Transactions, Vol. 42, No. 2, 150-154

26. Narayan Sunny.(2015). Correlation between in cylinder pressure and noise emissions from engines, Journal of Kones power train and Transport, Vol. 22, No. 1, 243-254.

27. Mahroogi, F.O., Narayan, S., Gupta, V.(2018). Acoustic transfer function in gasoline engines, International Journal of Vehicle Noise and Vibration, Vol. 14, No. 3, 270-280.

28. Narayan, S., Gupta, V.(2018).Numerical analysis of secondary motion of piston skirt in engines, International Journal of Acoustics and Vibrations, Vol. 23, No. 4, 557-565.

29. Narayan, S.(2015). Piston slap noise in engines, International Journal of Applied Engineering Research,Vol. 8, No. 14,1695-1700.

30. Narayan,S.(2015).Analysis of Piston Slap Motion, IJAME, Vol. 20, No. 2, 445-450. 
31. Narayan, S.(2015). Modeling of Noise Radiated from Engines, SAE Technical Paper 2015-01-0107.

32. Kaisan M.U., Abubakar S., Ashok B., Balasubramanian Dhinesh, Narayan S., Grujic Ivan\& Stojanovic Nadica.(2018). Comparative analyses of biodiesel produced from jatropha and neem seed oil using a gas chromatography-mass spectroscopy technique, Biofuels, Taylor and Francis, DOI: 10.1080/17597269.2018.1537206.

33. Mahroogi Faisal O., Narayan S.(2020). A recent review of hybrid automotive systems in Gulf Corporation Council (GCC) region, Proceedings of the Institution of Mechanical Engineers, Part D: Journal of Automobile, SAGE Publications, Volume 233,No.14, 3579-3587. DOI:10.1177/0954407019836055

34. Narayan S.(2019). Combustion monitoring in engines using accelerometer signals, Journal of Vibroengineering, Vol. 21, No. 6, 1552-1563.

35. Narayan S.(2013). Wavelet analysis of diesel engine noise, Journal of Engineering and Applied Sciences, Vol. 8, No. 8,255-259., DOI:10.3923/jeasci.2013.255.259

36. Narayan Sunny.(2013). Piston Slap Noise in engines, International Journal of Applied Engineering Research, Vol. 8, No.14,1695-1700.

37. Narayan Sunny.(2013). Effect of dwell time on noise radiated from diesel engine, International Journal of Applied Engineering Research, Vol. 8, No. 11, 13391347.

38. Alsagri Ali Sulaiman, Gupta Vipul, Narayan S.(2018). Design and analysis of hybrid automotive suspensionsystem, International Journal of Mechanical and Production Engineering Research and Development (IJMPERD), Vol. 9, No. 4, 637-642.
39. Alsagri Ali Sulaiman, Mahroogi Faisal O., Narayan S.(2018). Design and analysis of Double Wishbone suspension systems for automotive applications, International Journal of Mechanical and Production Engineering Research and Development (IJMPERD), Vol. 9, No. 4, 1433-1442.

40. Narayan S.(2015). Analysis of noise emitted from diesel engines. Journal of Physics Conference Series 12/2015;662(1):012018., DOI:10.1088/1742659 6/662/1/012018.

41. Mahroogi Faisal O., Narayan S.(2019). Dynamic- analysis-of-piston-secondary-motion-using FEM method, Proceedings of the 26th International Congress on Sound and Vibration, Montreal bridges, ISSN 2329-3675, ISBN 978-1-9991810-0-0.

42. Narayan S.(2015). Effects of Various Parameterson Piston Secondary Motion, SAE Technical Paper2015-01-0709.

43. Grujic, I., Stojanovic, N., Pesic, R., Davinic, A., Narayan, S.(2020).Numerical analysis of IC engine operation with high-pressure hydrogen injection, Transactions of FAMENA, Vol.44, No. 1, 55-66.

44. Abubakar, S., Anafi F.O., Kaisan, M.U., Umar, S., Umar, U.A.(2020). Comparative analyses of experimental and simulated performance of a mixed-mode solar dryer, Proceedings of the Institution of Mechanical Engineers, Part C: Journal of Mechanical Engineering Science, Vol. 234,No.7, 1393-1402.

45. Stojanovic, N., Ghazaly, N.M., Grujic, I., Glisovic, J., Narayan, S.(2020). Influence of size of ventilated brake disc's ribs on air fl ow velocity, International Journal of Advanced Science and Technology, Vol.29, No.1, 637-647. 